\title{
Safety and improvement in exercise tolerance with interval training vs moderate-intensity continuous training in heart disease patient of very high cardiovascular risk
}

\section{Seguridad y mayor tolerancia al esfuerzo con entrenamiento interválico en comparación con el entrenamiento de intensidad moderada continua en cardiópatas de riesgo cardiovascular muy alto}

\author{
Alfredo D. Pineda-García ${ }^{1 *}$, Jorge A. Lara-Vargas ${ }^{1}$, Andrés Ku-González¹, Víctor J. Lastra-Silva1, \\ Rodolfo Arteaga ${ }^{1}$, and Juan A. Pineda-Juárez ${ }^{2}$ \\ ${ }^{1}$ Cardiac Rehabilitation Department, Modular Services Division, Mexican Faculty of Medicine, Universidad La Salle; ${ }^{2}$ Clinical Research Department. \\ Centro Médico Nacional 20 de Noviembre, Instituto de Seguridad y Servicios Sociales de los Trabajadores del Estado, Mexico City, Mexico
}

\begin{abstract}
Objective: Evaluate safety and effects of training at moderate and high intensity intervals (MIIT, HIIT) compared to continuous moderate intensity training (MICT) in heart disease patient with very high cardiovascular risk (CVR). Method: Quasi-experimental study of 81 patients in a cardiac rehabilitation (CR) program, after risk stratification, all patients presented at least 2 factors with high CVR. All patients were provided supervised concurrent training: aerobic: initially 2 weeks MICT. Subsequently MICT group with same prescription, MIIT 3 intervals of 3 'to 70-80\% FCR with active pause exercise of 3' to 60 a $70 \%$ FCR, HIIT 3 intervals of 3'a 80-90\% FCR with active pause exercise of 3 ' 70 a $80 \%$ FCR, resistance training 3 weekly sessions isotonic exercises and 1 calisthenics and multidisciplinary intervention. Results: 81 patients assigned to: 61 MICT group, 13 MIIT and 7 HIIT, no significant differences were observed. Percentage gains were obtained in METs-load 45\%, $60 \%$ and $86 \%(p=0.17)$ and watts 51,44 and 48 in MICT, MIIT, HIIT respectively $(p=0.54)$. Although there are no statistical significant intergroup differences if there is a greater improvement in MET-load in the HIIT group. There was no adverse outcome in any training. Conclusions: In very high cardiovascular risk heart disease patient, supervised interval training (MIIT/HIIT) is safe, with a tendency to greater improvement in exercise tolerance (METS-Ioad) with HIIT compared to MICT.
\end{abstract}

Key words: MICT. MIIT. HIIT. Cardiovascular risk.

\section{Resumen}

Objetivo: Evaluar la seguridad y el efecto del entrenamiento por intervalos de moderada y alta intensidad (EIMI, EIAI) y compararlo con el entrenamiento de intensidad moderada continua (EIMC) en pacientes de riesgo cardiovascular (RCV) muy alto. Método: Estudio cuasi experimental de 81 pacientes que ingresaron al programas de rehabilitación cardíaca y prevención secundaria (PRHCPS); en la estratificación de riesgo, todos los pacientes presentaron $\geq 2$ factores de RCV alto. Entrenamiento concurrente: aeróbico supervisado: 2 semanas de entrenamiento de base de EIMC; luego el grupo

\section{Correspondence:}

*Alfredo D. Pineda-García

E-mail: pinedacardio@gmail.com
Date of reception: 15-02-2020

Date of acceptance: 22-04-2020

DOI: 10.24875/ACME.M21000194
Available online: 19-07-2021 Arch Cardiol Mex (Eng). 2021;91(2):149-155 www.archivoscardiologia.com 2604-7063 / @ 2020 Instituto Nacional de Cardiología Ignacio Chávez. Published by Permanyer. This is an open access article under the CC BY-NC-ND license (http://creativecommons.org/licenses/by-nc-nd/4.0/). 
EIMC con la misma prescripción, EIMI a 3 intervalos de 3' al 70 a $80 \%$ de FCR con pausas activas de 3' al 60 a $70 \%$ de FCR; EIAl, 3 intervalos de 3' a 80 a 90\% de FCR con pausas activas de 3' al 70 a $80 \%$ de FCR, entrenamiento de fuerza con tres sesiones semanales de ejercicios isotónicos y una de calistenia e intervención multidisciplinaria. Resultados: 81 pacientes asignados en tres grupos: 61 a EIMC, 13 a EIMI y 7 a EIAI, sin diferencias significativas en las variables epidemiológicas. Hubo ganancias porcentuales en MET-carga de 45\%,60\% y $86 \%$ ( $p=0.17)$ y carga-vatios de 51 , 44 y 48 en EIMC, EIMI, EIAI, respectivamente $(p=0.54)$. A pesar de no existir diferencias estocásticamente significativas intergrupales, sí se registró una ganancia mayor en MET-carga en el grupo de EIAI. No se observó desenlace adverso en ningún tipo de entrenamiento. Conclusiones: En cardiópatas de riesgo cardiovascular muy alto, el entrenamiento interválico EIMI/EIAI supervisado es seguro, con tendencia a mayor ganancia en tolerancia al esfuerzo (MET-carga) con el EIAl en comparación con el EIMC.

Palabras clave: EIMC. EIMI. EIAI. Alto riesgo.

\section{Introduction}

Cardiovascular disease (CVD) is currently the leading cause of mortality in the world, including Mexico. Cardiac rehabilitation and secondary prevention (CRSP) programs have been shown to be effective in reducing cardiovascular and all-cause mortality, decreasing heart attack recurrence and improving quality of life, with these outcomes being dose-dependent ${ }^{1-3}$. Exercise prescription and cardiovascular risk grading are the pillars of intervention correct execution ${ }^{4}$.

Moderate-intensity continuous training (MICT) has usually been the basis of training in cardiac rehabilitation and secondary prevention (CRSP) programs. However, in more recent evidence, moderate-intensity interval training (MIIT) and high-intensity interval training (HIIT) have been shown to be safe and to obtain better gains in peak oxygen consumption $\left(\mathrm{VO}_{2} \mathrm{p}\right)$ in patients stratified as of low to moderate cardiovascular risk (CVR), in comparison with MICT. This evidence is supported by the fact that the achievement of higher thresholds (VT2 and $\mathrm{VO}_{2} \mathrm{p}$ ) in healthy athletes can be replicated in patients with heart disease regardless of their risk grading ${ }^{1-3,5}$. In addition, Mexican population characteristics share multiple variables of high cardiovascular risk, and patients are classified as of "very high" CVR.

So far, the effects of MIIT/HIIT on safety and exercise tolerance gain in comparison with MICT in very-high CVR cardiac patients are unknown. The authors' hypothesis establishes that if higher-intensity interventions (at interval tolerance) generate a larger training volume, and given that this is directly correlated with higher gains in $\mathrm{VO}_{2} \mathrm{p}$ and angiogenic, autonomic and endothelial regulation results in the long term ${ }^{6,7}$, without suffering major complications, then patients at very high cardiovascular risk could obtain better results with HIIT/MIIT in terms of efficiency and safety than those undergoing MICT. The purpose of this study is to evaluate the safety and effects of interval training (MIIT/ HIIT) in comparison with moderate intensity continuous training in patients at very high cardiovascular risk.

\section{Material and methods}

Quasi-experimental study of 81 patients who joined the CRSP program, after CVR stratification by exercise test; all patients had at least two high CVR factors (Table 1). All individuals underwent cycle ergometer or treadmill aerobic training according to the principle of training individualization for four to six weeks, with five 30-minute weekly sessions; all patients underwent two weeks of basic MICT, with 5-min warm-up, 20 min at $70 \%$ of heart rate reserve (HRR) according to Karvonen formula, and 5 min for cooling down; based on evolution, medical criteria and cardiovascular risk, patients were subsequently categorized for MIIT-HIIT implementation. The MICT group had the same established prescription; the MIIT group, 5-min warm-up, three 3-min intervals at $70-80 \%$ of $\mathrm{HRR}$ with 3 -min active pauses at $60-70 \%$ of HRR, followed by 5 min for cooling down; and for the HIIT group, 5-min warm-up, three 3-min intervals at $80-90 \%$ of $\mathrm{HRR}$ with 3 -min active pauses at $70-80 \%$ of HRR, and 5 min for cooling down (Fig. 1). All patients received concurrent treatment with strength training on three weekly sessions with isotonic exercise and a calisthenics session, as well as group interventions for nutrition and cardiovascular risk factors control, psycho-emotional care, occupational therapy, and anti-smoking and sexuality techniques.

All sessions were supervised by a rehabilitation cardiologist and safety scrutiny was performed before the sessions, which were monitored by telemetry, with blood pressure recording before, during and after the dynamic-static exercise sessions. For statistical analysis, the obtained data were captured in a Microsoft Excel 
Table 1. Cardiovascular high-risk factors

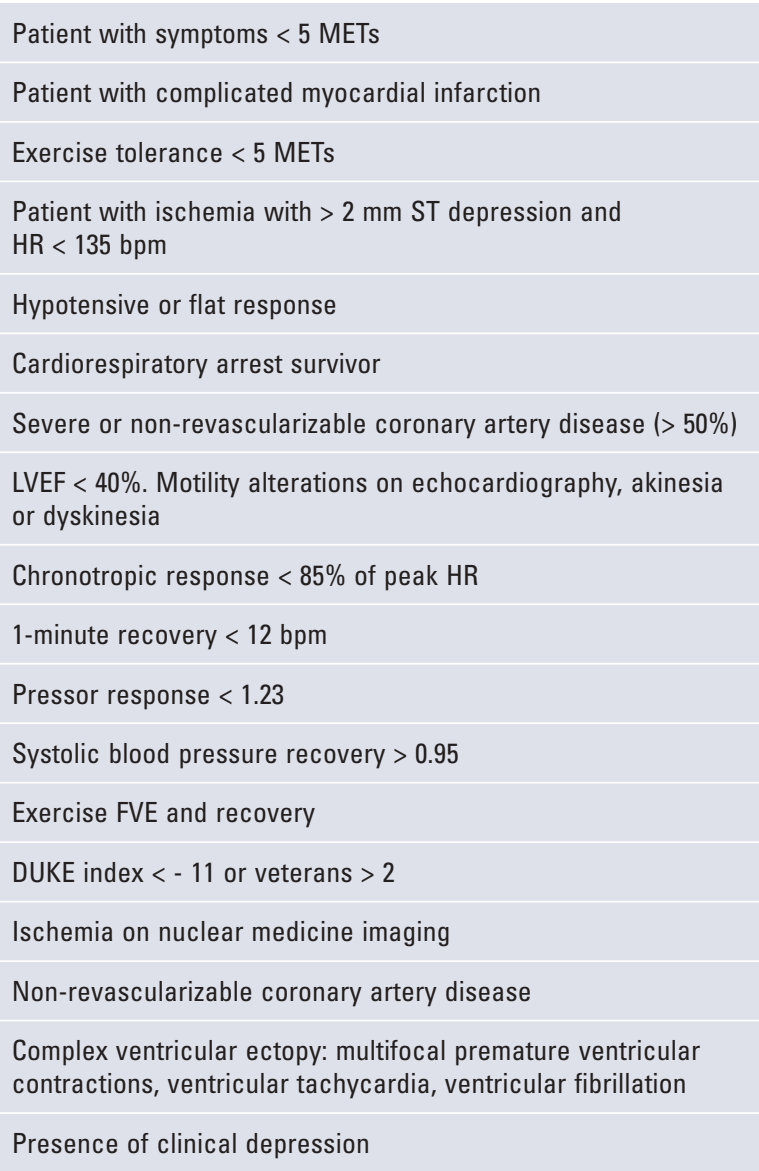

MET: exercise tolerance (metabolic equivalent of task); HR: heart rate; LVEF: left ventricular ejection fraction; FVE: frequent ventricular extrasystoles; NM: nuclear medicine.

spreadsheet and analyzed with the SPSS v22 statistical program. For continuous quantitative variables, the results were expressed as medians and percentiles, and as frequency and percentages when variables were categorical. For the comparison between study groups, Kruskall-Wallis test was used for continuous variables and Pearson's chi-square test for categorical variables. For the comparison between study groups after the intervention, Kruskall-Wallis test was used.

\section{Results}

Eighty-one patients, distributed in three groups, were included in the study: MICT group, with 61 patients and average age of 65 years, with 44 males $(72.1 \%)$ and average LVEF of $52 \%$; MIIT group, with 13 patients and average age of 70 years, with 9 males (62.3\%) and average LVEF of $59 \%$; HIIT group, with 7 patients and average

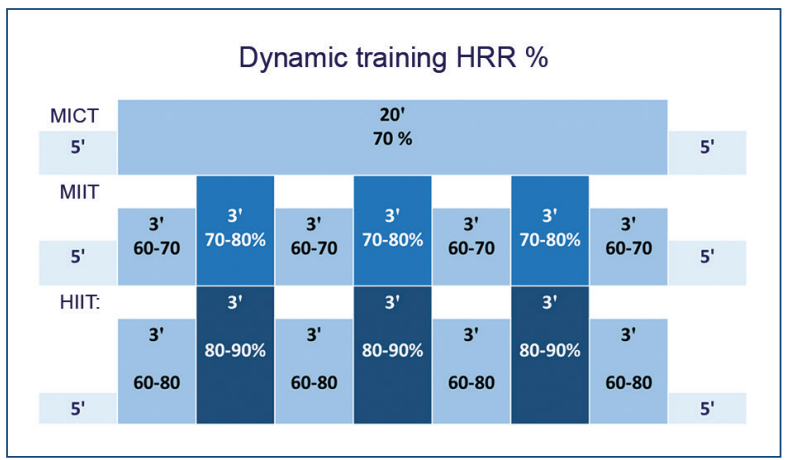

Figure 1. Interval training and moderate continuous training. HRR: heart rate reserve percentage; MICT: moderate-intensity continuous training; MIIT: moderate-intensity interval training; HIIT: high-intensity interval training. (author: Alfredo D. Pineda García).

age of 66 years, with 6 males (85.71\%) and average LVEF of $56 \%$, with no significant difference $(p=0.03)$.

No significant differences were identified between gender $(p=0.80)$, age $(p=0.36)$, or $\operatorname{LVEF}(p=0.3)$. Cardiovascular risk factors such as obesity, smoking, type 2 diabetes mellitus (DM2), high blood pressure (HBP), dyslipidemia and sexuality were obtained, without significant differences between epidemiological variables being observed (Table 2). Most prevalent diagnoses were ischemic heart disease followed by heart failure. Percentage gains of $45 \%, 60 \%$ and $86 \%$ $(p=0.17)$ in MET-load and 51, 44 and 48 workload-watts were obtained for MICT, MIIT and HIIT, respectively $(p=0.54)$. Despite the absence of stochastically significant intergroup differences, a gain in MET-load was recognized in the HIIT group $(85.74 \%, p=0.171)$. There were no cardiovascular adverse episodes in any of the training sessions (Table 3).

Percentage gains by percentile were as follows: for the MICT group, $24.66 \%$ at $25^{\text {th }}$ percentile, $45 \%$ at $50^{\text {th }}$ percentile, $67.59 \%$ at $75^{\text {th }}$ percentile; for the MIIT group, MET-load gain was $26.77 \%$ at $25^{\text {th }}$ percentile, $60 \%$ at $50^{\text {th }}$ percentile and $94.84 \%$ at $75^{\text {th }}$ percentile; in the HIIT group, the largest gain was identified with $42.14 \%$ at $25^{\text {th }}$ percentile, $85.74 \%$ at $50^{\text {th }}$ percentile and $157.5 \%$ at $75^{\text {th }}$ percentile; a trend towards larger gain is noted in the HIIT group, but without it being statistically significant, $p=0.171$ (Fig. 2).

\section{Discussion}

Since the 1960s, CRSP programs by transdisciplinary activities integration have had the purpose to 
Table 2. Sample characteristics

\begin{tabular}{|c|c|c|c|c|}
\hline Variable & MICT $(n=61)$ & MIIT (n = 13) & HIIT $(n=7)$ & $\mathbf{p}$ \\
\hline $\begin{array}{l}\text { Gender, n (\%) } \\
\text { Females } \\
\text { Males }\end{array}$ & $\begin{array}{l}17(27.9 \%) \\
44(72.1 \%)\end{array}$ & $\begin{array}{l}4(30.76 \%) \\
9(69.23 \%)\end{array}$ & $\begin{array}{l}1(14.28 \%) \\
6(85.71 \%)\end{array}$ & 0.80 \\
\hline Age (years) & $65(56.5-70)$ & $70(56.5-74.5)$ & $66(56-70)$ & 0.36 \\
\hline BMI & $27.73(25.39-30.52)$ & $28.71(24.89-30.88)$ & $26.18(23.45-28.95)$ & 0.61 \\
\hline Obesity, n (\%) & $29(47.50 \%)$ & $8(61.50 \%)$ & $2(28.60 \%)$ & 0.446 \\
\hline Smoking, $\mathrm{n}(\%)$ & $37(60.70 \%)$ & $6(46.20 \%)$ & $7(100 \%)$ & 0.52 \\
\hline $\mathrm{DM} 2, \mathrm{n}(\%)$ & $26(42.60 \%)$ & $5(38.50 \%)$ & $3(42.90 \%)$ & 1 \\
\hline HBP, n (\%) & $43(70.50 \%)$ & $10(76.90 \%)$ & $4(57.10 \%)$ & 0.65 \\
\hline Dyslipidemia & $36(59.00 \%)$ & $10(76.90 \%)$ & $4(57.10 \%)$ & 0.537 \\
\hline Sexuality $(\%)$ & $29(47.50 \% \%)$ & $9(69.20 \%$ & $4(57.10 \%)$ & 0.301 \\
\hline IHD, n (\%) & $54(88.50 \%)$ & $11(84.50 \%)$ & $7(100 \%)$ & 0.70 \\
\hline $\mathrm{HF}, \mathrm{n}(\%)$ & $23(37.70 \%)$ & $3(23.10 \%)$ & $1(14.30 \%)$ & 0.43 \\
\hline$A F, n(\%)$ & $2(3.30 \%)$ & $1(7.70 \%)$ & 0 & 0.57 \\
\hline Valvular heart disease, $\mathrm{n}(\%)$ & $10(16.40 \%)$ & $1(7.70 \%)$ & 0 & 0.62 \\
\hline TAVI, n (\%) & $3(4.90 \%)$ & $1(7.70 \%)$ & 0 & 0.686 \\
\hline MITRACLIP, n (\%) & $2(3.30 \%)$ & 0 & 0 & 1 \\
\hline $\mathrm{PAD}, \mathrm{n}(\%)$ & $1(1.60 \%)$ & $1(7.70 \%)$ & $1(14.30 \%)$ & 0.14 \\
\hline Congenital heart disease (\%) & $1(1.60 \%)$ & $1(7.70 \%)$ & 0 & 0.43 \\
\hline Dilated cardiomyopathy, n (\%) & $6(9.80 \%)$ & $1(7.70 \%)$ & 0 & 1 \\
\hline Device (\%) & $2(3.30 \%)$ & $2(15.40 \%)$ & 0 & 0.15 \\
\hline LVEF \% & $52(39.5-61)$ & $59(44-65)$ & 56 (49-59) & 0.3 \\
\hline
\end{tabular}

Data are presented as medians and percentiles (p25-p75) or $\mathrm{n}(\%)$. BMI: body mass index ( $\left.\mathrm{kg} / \mathrm{m}^{2}\right)$; DM2: type 2 diabetes mellitus; HBP: high blood pressure; IHD: ischemic heart disease; HF: heart failure; AF: atrial fibrillation; TAVI: transcatheter aortic valve insertion; PAD: peripheral artery disease; LVEF: left ventricular ejection fraction.

improve the quality of life of patients and achieve the most complete possible reincorporation to society $^{8}$, and have expanded their indication to populations at high risk of cardiovascular disease, i.e., individuals who have several concurrent cardiovascular risk factors ${ }^{3}$.

Risk grading prior to starting a CRSP program is a critical part for exercise evaluation and prescription in individuals who join such programs; based on the above, different world associations have categorized patients at low, medium and high cardiovascular risk using clinical variables and conventional stress testing ${ }^{4}$, such as exercise tolerance, presence of ischemic threshold on conventional exercise test, chronotropic response, 1-minute heart rate recovery, pressor response, systolic blood pressure recovery and presence of complex ventricular ectopy (FVE) ${ }^{9-17}$. However, in clinical reality, a single patient can harbor multiple high cardiovascular risk variables. In this study, all evaluated patients had more than one cardiovascular risk factor, which turns them into subjects at high cardiovascular risk and, therefore, they can be classified as "very high cardiovascular risk" patients. This trial is the first to evaluate the effect of MICT, MIIT and HIIT in patients at very high cardiovascular risk.

Interval training consists of a series of repeated episodes of higher intensity work intervals alternated with recovery pauses (light- or mild-intensity exercises) ${ }^{18}$. HIIT intermittent nature allows less fatigue owing to recovery periods, which leads to achieving higher effort intensity during the interval. As a result, the adenosine 
Table 3. CRSP program results

\begin{tabular}{|l|c|c|c|c|}
\hline Variable & MICT (n= 61) & MIIT (n= 13) & HIIT (n= 7) & p \\
\hline BORG & $13(12-13)$ & $13(12-13.5)$ & $12(12-13)$ & 0.157 \\
\hline Initial METs & $6.2(4.6-7.2)$ & $4(3.05-6.2)$ & $4.1(2.5-11.3)$ & 0.15 \\
\hline Final METs & $9(7.2-10.7)$ & $7.1(5.2-9.0)$ & $8.1(8-16.4)$ & 0.095 \\
\hline MET gain \% & $45(24.66-67.59)$ & $60(26.77-94.84)$ & $85.74(42.14-157.5)$ & 0.171 \\
\hline Initial METs Max \% & $83(58.5-101.5)$ & $55(42-84)$ & $86(40-128)$ & 0.158 \\
\hline Final METs Max \% & $115(94-138)$ & $89(76.5-122.5)$ & $127(72-182)$ & 0.216 \\
\hline Initial workload (watts) & $32(24-40)$ & $25.5(13-38.5)$ & $30(16-54)$ & 0.426 \\
\hline Final workload (watts) & $50(37.75)$ & $42.5(31.5-57)$ & $42(39-75)$ & 0.390 \\
\hline Gain \% (watts) & $51.51(25.83-84.29)$ & $44.29(30.5-81.93)$ & $48.64(34.32-118.75)$ & 0.544 \\
\hline
\end{tabular}

Data are presented as medians and percentiles (p25-p75) or $\mathrm{n}(\%)$. BORG: perceived exertion scale, 6-12; MET: metabolic equivalent (3.5 $\left.\mathrm{mL} 0{ }_{2} / \mathrm{kg} / \mathrm{min}\right)$;

Initial METs Max \%: initial theoretical MET-load percentage; Final METs Max \%: final theoretical MET-load percentage; initial workload in watts; MICT: moderate-intensity continuous training; MIIT: moderate-intensity interval training; HIIT: high-intensity interval training.

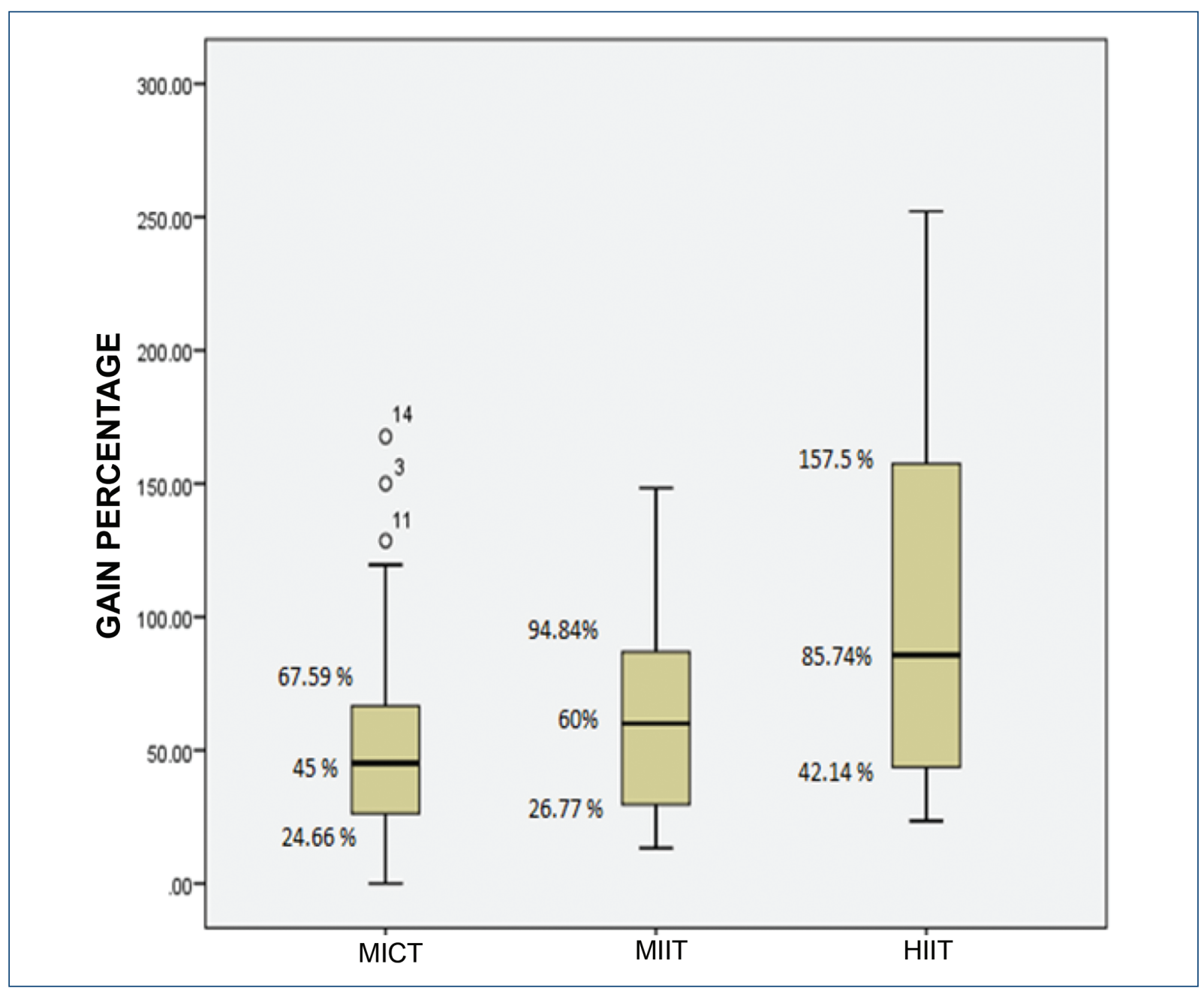

Figure 2. Gain percentage in METs. Percentage of $\mathrm{VO}_{2}$ gains in the three intervention groups: $45 \%$ for $\mathrm{MICT}, 60 \%$ for MIIT and $85.74 \%$ for HIIT, ( $p=0.17)$. MICT: moderate-intensity continuous training; MIIT: moderate-intensity interval training; HIIT: high-intensity interval training. 
triphosphate-phosphocreatine (ATP-PC) and glycolysis energy systems are used time and time again, in such a way that an increase in skeletal muscles energy capacity is promoted. In addition, multiple recovery periods allow stroke volume to reach its highest values several times during a single exercise period rather than just once with a continuous exercise period ${ }^{19}$.

HIIT has shown remarkable benefits in the decrease of cardiovascular risk factors, improved fitness and benefits in all-cause mortality. HIIT has also been reported to be more effective than MICT in reducing body fat due to higher energy expenditure during training. Other publications have demonstrated that the cardiovascular adaptations occurring in HIIT are similar, and even superior in some cases, to those obtained by MICT $^{19}$. Since the 1980 s, the benefits of high-intensity interval training (HIIT) have been investigated in patients with coronary artery disease. In the meta-analysis by Martland et al. ${ }^{20}$ evidence was shown that HIIT improves cardiorespiratory function, body composition, serum glucose values, glycemic control, endothelial and cardiovascular function, heart rate, inflammatory markers, exercise tolerance, muscle mass, as well as improvements in states of anxiety and depression ${ }^{20}$. So far, positive effects have been shown on maximum $\mathrm{VO}_{2}$ gain, with some contrasting results in patients with high cardiovascular risk ${ }^{17,21-34}$. However, big questions prevail, for example, who is the patient that is eligible for interval treatment? In which individuals should it not be used? Most studies have been carried out in relatively young male subjects, with normal left ventricular function, aerobic capacity $>7 \mathrm{MET}$, stable coronary artery disease and absence of signs or symptoms of residual myocardial ischemia or ventricular arrhythmias ${ }^{9,18}$.

Since not all patients are suitable for HIIT, there is a similar but alternative model, i.e., moderate-intensity interval training (MIIT). This training method is often used at the same volume as MICT but with active pauses, just as structured in HIIT. It differs in that, instead of training patients with working intervals at $85-90 \%$ of HRR, a figure of $70-80 \%$ of HRR is used in cardiac patients, and with said pauses at between 60 and $70 \%$ of $\mathrm{HRR}^{18}$. Keteyian et al. ${ }^{35}$ describe three important effects with interval treatment: a) it incorporates the intermittent and potentially more favorable effects of working at intervals without patients exceeding current standards for prescribing exercise; b) it helps patients to work at the upper end of their training spectrum, which facilitates training progression for generating a shift to higher thresholds, and c) it promotes treatment adherence, since patients who use MIIT or HIIT refer that they "enjoy" their workout sessions better. They often report obtaining a "better" training with interval practices, regardless of using HIIT or MIIT. Among the results of this work, although there is no evidence of statistical significance in exercise tolerance gains evaluated by METs gain, a greater trend towards gains in initial and final MET percentage is observed in patients undergoing the interval modality, in particular with HIIT. In medical publications, by observing $\mathrm{VO}_{2} \mathrm{p}$ gains and their effect on morbidity and mortality, scientific research has accumulated evidence to transfer that effect to populations with heart disease. However, given that these are exertion intensities that can put patients with these characteristics at risk by subjecting them for two to four minutes to metabolic instability, structuring this treatment below ventilatory threshold 2 (maximum point of ventilatory efficiency) has been possible, in order to adapt them to these gains and with the lowest possible risk. For this reason, regarding the safety of this protocol, like the meta-analysis by Hannan et al. ${ }^{18}$, where the safety of interval training such as MICT was examined, no cardiovascular episodes requiring hospitalization or deaths were recorded. So far, as demonstrated in this study, these results have been replicated with a good safety margin, with no associated complications reported in the records.

\section{Limitations}

Due to the principle of training individualization, it is not possible for one type of training to be randomly established in patients who join the CRSP program; this has forced for methodology to dispense with randomization, with control groups based on selection criteria in compliance with ethical regulations for prescription and in accordance with cardiovascular risk stratification. Although all patients were provided concurrent training, there is no reliable method to assess the magnitude of static training in terms of exercise tolerance gain. Higher patient inclusion is required to reinforce the results of our sample. Measurements were made using $\mathrm{VO}_{2} \mathrm{p}$ calculated per workload and not through the reference standard, i.e., measurement with expired gas analysis.

\section{Conclusions}

In cardiac patients with very high cardiovascular risk, supervised MIIT/HIIT interval training is safe, with a trend towards greater exercise tolerance gain (METload) with HIIT in comparison with MICT. 


\section{Funding}

This research has not received any specific grant from public, commercial or non-profit sector agencies.

\section{Conflicts of interest}

The authors declare that they have no conflicts of interest.

\section{Ethical disclosures}

Protection of human and animal subjects. The authors declare that no experiments have been performed on humans or animals for this research.

Confidentiality of data. The authors declare that they have followed the protocols of their work center on the publication of patient data.

Right to privacy and informed consent. The authors have obtained informed consent from the patients or subjects referred to in the article. This document is in the possession of the corresponding author.

\section{References}

1. Wewege MA, Ahn D, Yu J, Liou K, Keech A. High-intensity interval training for patients with cardiovascular disease-is it safe? A systematic review. J Am Heart Assoc. 2018;7:e009305.

2. Gomes-Neto M, Durães AR, Conceição LSR, Saquetto MB, Ellingsen $\varnothing$, Carvalho VO. High intensity interval training versus moderate intensity continuous training on exercise capacity and quality of life in patients with heart failure with reduced ejection fraction: a systematic review and meta-analysis. International Journal of Cardiology. 261;134-141.

3. Maroto JM, Artigao-Ramírez R, Morales-Durán MD, de Pablo-Zarzosa C, Abraira V. Rehabilitación cardíaca en pacientes con infarto de miocardio. Resultados tras 10 años de seguimiento. Rev Esp Cardiol. 2005;58:1181-7.

4. França da Silva AK, da Costa de Rezende-Barbosa MP, Barbosa-Bernardo AF, Marques-Vanderlei F, Lopes-Pacagnelli F, Marques-Vandelei LC. Cardiac risk stratification in cardiac rehabilitation programs: a review of protocols. Rev Bras Cir Cardiovasc. 2014;29(2):255-65.

5. Quindry JC, Franklin BA, Chapman M, Humphrey R, Mathis S. Benefits and risks of high-intensity interval training in patients with coronary artery disease. Am J Cardiol. 2019;123(8):1370-1377.

6. Kim C, Choi HE, Lim YJ. The effect of cardiac rehabilitation exercise training on cardiopulmonary function in ischemic cardiomyopathy with reduced left ventricular ejection fraction. Ann Rehabil Med. 2016;40(4):647-656.

7. Lavie CJ, Ozemek C, Carbone S, Katzmarzyk PT1, Blair SN. Sedentary behavior, exercise, and cardiovascular health. Circ Res. 2019;124(5):799-815.

8. Mark DB, Hlatky MA, Harrell FE Jr, Lee KL, Califf RM, Pryor DB. Exercise treadmill score for predicting prognosis in coronary artery disease. Annals of Internal Medicine. 1987;106(6):793-800.

9. Dresing TJ, Blackstone EH, Pashkow FJ, Snader CE, Marwick TH Lauer MS. Usefulness of impaired chronotropic response to exercise as a predictor of mortality, independent of the severity of coronary artery disease. Am J Cardiol. 2000;86(6):602-9.

10. Cole CR, Blackstone EH, Pashkow FJ, Snader CE, Lauer MS. Heart-rate recovery immediately after exercise as a predictor of mortality. $\mathrm{N}$ Engl J Med. 1999;341(18):1351-7.

11. Shetler K, Marcus R, Froelicher VF, Vora S, Kalisetti D, Prakash M, et al. Heart rate recovery: validation and methodologic issues. J Am Coll Cardiol. 2001;38(7):1980-7.

12. Myers J, Prakash M, Froelicher V, Do D, Partington S, Atwood JE. Exercise capacity and mortality among men referred for exercise testing. New England Journal of Medicine. 2002;346(11):793-801.
13. McHam SA, Marwick TH, Pashkow FJ, Lauer MS. Delayed systolic blood pressure recovery after graded exercise: an independent correlate of angiographic coronary disease. J Am Coll Cardiol. 1999;34(3):754-9.

14. Frolkis JP, Pothier CE, Blackstone EH, Lauer MS. Frequent ventricular ectopy after exercise as a predictor of death. N Engl J Med. 2003;348: 781-790.

15. Lauer MS, Okin PM, Larson MG, Evans JC, Levy D. Impaired heart rate response to graded exercise: prognostic implications of chronotropic Incompetence in the Framingham Heart Study. Circulation. 1996;93:15201526.

16. Morrow K, Morris CK, Froelicher VF, Hideg A, Hunter D, Johnson E, et al. Prediction of cardiovascular death in men undergoing noninvasive evaluation for coronary artery disease. Annals of Internal Medicine. 1993;118(9):689-695.

17. Ilarraza-Lomelí H. Rehabilitación y prevención cardiovascular: el complemento necesario a la terapéutica de hoy. Arch Cardiol Mex. 2003;73: 247-252.

18. Hannan AL, Hing W, Simas V, Climstein M, Coombes JS, Jayasinghe R. High-intensity interval training versus moderate intensity continuous training within cardiac rehabilitation a systematic review and meta-analysis. Open Access Journal of Sports Medicine. 2018;9:1-17.

19. Milanović Z, Sporiš G, Weston M. Effectiveness of high-intensity interval training (hit) and continuous endurance training for VO2max improvements: a systematic review and meta-analysis of controlled trials. Sports Med. 2015;45(10):1469-81.

20. Martland R, Mondelli V, Gaughran F, Stubbs B. Can high-intensity interval training improve physical and mental health outcomes? A metareview of 33 systematic reviews across the lifespan. J Sports Sci. 2020; 38(4):430-469.

21. Nystoriak MA, Bhatnagar A. Cardiovascular effects and benefits of exercise. Front Cardiovasc Med. 2018;5(135):1-11.

22. Gibb AA, Epstein PN, Uchida S, Zheng Y, McNally LA, Obal D, et al. Exercise-induced changes in glucose metabolism promote physiological cardiac growth. Circulation. 2017;136:2144-57.

23. Linke A, Erbs S, Hambrecht R. Effects of exercise training upon endothelial function in patients with cardiovascular disease. Frontiers in Bioscience. 2008;13:424-432

24. Hambrecht R, Wolf A, Gielen S, Linke A, Hofer J, Erbs S, et al. Effect of exercise on coronary endothelial function in patients with coronary artery disease. N Engl J Med. 2000;342(7):454-60.

25. Ertek S, Cicero A. Impact of physical activity on inflammation: effects on cardiovascular disease risk and other inflammatory conditions. Arch Med Sci. 2012;8(5):794-804.

26. Bousselmi R, Lebbi MA, Ferjani M. Myocardial ischemic conditioning: Physiological aspects and clinical applications in cardiac surgery. J Saudi Heart Assoc. 2014;26(2):93-100.

27. Winzer EB, Woitek F, Linke A. Physical activity in the prevention and treatment of coronary artery disease. J Am Heart Assoc. 2018;7(4):1-15.

28. Bruning RS, Sturek M. Benefits of exercise training on coronary blood flow in coronary artery disease patients. Prog Cardiovasc Dis. 2015;57(5):443-453.

29. Sandri M, Adams V, Gielen S, Linke A, Lenk K, Kränkel N, et al. Effects of exercise and ischemia on mobilization and functional activation of blood-derived progenitor cells in patients with ischemic syndromes: results of 3 randomized studies. Circulation. 2005;111(25):3391-3399.

30. Popovic D, Kumar N, Chaudhry S, Bagai A, Arena R, Kumar N. Improvements in key cardiopulmonary exercise testing variables following cardiac rehabilitation in patients with coronary artery disease. Cardiopulmonary Exercise Testing in Cardiac Rehabilitation. 2018;38(5):E5-E8.

31. Ribeiro F, Alves AJ, Teixeira M, Miranda F, Azevedo C, Duarte JA. Exercise training enhances autonomic function after acute myocardial infarction: a randomized controlled study. Rev Port Cardiol. 2012;31(2):135-141.

32. Hambrecht R, Niebauer J, Marburger C, Grunze M, Kälberer B, Hauer K et al. Various intensities of leisure time physical activity in patients with coronary artery disease: effects on cardiorespiratory fitness and progression of coronary atherosclerotic lesions. J Am Coll Cardiol. 1993; 22(2):468-77.

33. Hambrecht R, Adams V, Erbs S, Linke A, Kränkel N, Shu Y, et al. Regular physical activity improves endothelial function in patients with coronary artery disease by increasing phosphorylation of endothelial nitric oxide synthase. Circulation. 2003;107(25):3152-8.

34. Badrov MB, Wood KN, Lalande S, Sawicki CP, Borrell LJ, Barron CC, et al. Effects of 6 months of exercise-based cardiac rehabilitation on autonomic function and neuro-cardiovascular stress reactivity in coronary artery disease patients. J Am Heart Assoc. 2019;8(17):1-10.

35. Keteyian SJ. High intensity interval training in patients with cardiovascular disease: a brief review of physiologic adaptations and suggestions for future research. Journal of Clinical Exercise Physiology. 2013;2(1):13-19. 